\title{
MODELING OF SLUMP VALUE AND DETERMINATION OF INFLUENTIAL VARIABLES WITH REGRESSION APPROACH
}

\author{
Eri Cahyani $^{* 1}$, Ari Wibowo ${ }^{2}$, Indradi Widjatmiko ${ }^{2}$ \\ ${ }^{1}$ Student, Magister of Construction Management, Departement of Civil Engineering, \\ Faculty of Civil Engineering, Brawijaya of University \\ 2 Doctoral, Departement of Civil Engineering, Faculty of Engineering, Brawijaya of \\ University \\ *Corresponding Author: ericahyani.r@gmail.com
}

\begin{abstract}
There are many factors underlying the instability of the consistency of the concrete mixture. The consistency of the concrete mixture was measured using a slump test. Slump tests are commonly used in measuring the quality of fresh concrete. The instability of the slump value becomes an unsolved problem. To facilitate predicting slump values, modeling is needed to reduce variations in concrete job mix. Regression has been known as the basic method of predictive modeling. Collected data is divided according to the ratio of sand to: $<38 \%, 38-44 \%$ and $>44 \%$. The sand ratio data $<38 \%$ is the most suitable model, because it has a value of R2 0.957, adj. R2 0.897 and MSE 0.31. The most influential variable is water and sand. The resulting modeling is adjusted to the range of data collected.
\end{abstract}

Keywords : slump, flexibility, consistency, regression, prediction, quality management

\section{INTRODUCTION}

Concrete is composite building material which adjustable character. Must be considered, the main properties of concrete are strength, workability and durability. Determining the nature of concrete can effect the proportion of material. Proportion of material based on structural requirement and construction conditions such as: ambient temperature, construction methods. Error measuring material proportions can cause concrete mixture problems such as: segregation, bleeding, less density (honeycomb), cracks, etc. The main material of concrete is paste as a binder and aggregate as a filler. Pasta is formed from water and cement, while the aggregates are sand and gravel. Other materials used to enrich the concrete properties are admixture and additive. Things to keep in mind, the more complex the materials used, control of concrete quality increasingly difficult.

The mixture result from batch to batch can be different (Murdock, 1986) [1]. There are many factors that affect for example: material especially water calculations, different material sources, material availability and way of storage, and etc. Management of concrete production supervision should be done carefully. As stated by JIS in JSCE, 2010 that the search process of concrete mixtures was carried out with several adjustment [2]. The adjustment are the amount of water, the amount of cement, the percentage of sand and the amount of additional material. Fine mixture resulted by tested the quality of concrete.

Concrete quality problems also occur when fresh concrete is transported from batchingplant to site. Changing ambient temperature, transit time, poor management in the field such as damaged pouring equipment or other things, can reduce the quality of fresh concrete. Fresh concrete can lose plasticity when not immediately poured. Murdock states that it is necessary to test the consistency of concrete to maintain workability. However, repeated testing procedures can interfere with 
the concrete production process. Inconsistent consistency values attract some researchers to examine modeling in helping determine the value of slump.

Previous research uses several methods, namely: regression, Artificial Neural Network (ANN), Group Data Handling Algorithm (GDMH), Partial Least Square (PLS), Least Square-Support Vector Regression (LS-SVR). The most common method is backpropagation ANN. All research that has been done is only looking for modeling that is accurate in predicting slump values.

This study will predict the slump value by multiple linear regression methods. This method was chosen because it is a basic method of prediction in statistics. The variables included are: cement, water, sand, $5-10 \mathrm{~mm}$ gravel, $10-20 \mathrm{~mm}$ gravel, $20-30 \mathrm{~mm}$ gravel, rock dust, fly ash, retarder and superplatisizer. Varying compressive strenghts from BO, K125 , K-175, K-225, K-250, K-275, K-300, K$350, \mathrm{~K}-400, \mathrm{~K}-450$ to $\mathrm{K}-500$ used in this research. Data was obtained from several batchingplant in Malang and one batchingplant from Blitar. The final product of this study is to get the appropriate model in predicting the slump and the most influential predictor variable on the value of slump. This study is expected to facilitate the management of concrete quality later.

\section{LITERATURE REVIEW}

\subsection{Workability}

Workability means that it is easy to do. Fresh concrete is expected to be easily moved, transported, poured, filled in the mold. Concrete must be able to flow well to the corners of the formwork, fill it perfectly and tightly without holes. When fresh concrete is worked, the mixture is still homogeneous, coherent and stable when worked and easily compacted. So fresh concrete must be easily mobilized, compacted and have the right consistency to easily fill the mold well.

Concrete production that has consistent workability is an indication of good concrete quality management. Good performance will produce concrete with good standard deviation of compressive strength.

\subsection{Slump Test}

The slump value in the field cannot be closely monitored as in laboratory production
(SNI 1972: 2008) [3]. Slump value has several classifications as in Table 1. Slump test results can be wrong if the testing process is not according to the procedure. The process of inserting concrete in an abrasive cone until stabbing and removal of the mold must be done well, should not be more than 5 seconds and must be straight.

Table 1. Workability Classsification

\begin{tabular}{lll}
\hline Slump value & Workability & Function \\
\hline $0-25 \mathrm{~mm}$ & Dry & $\begin{array}{l}\text { Road } \\
\text { construction }\end{array}$ \\
\hline $10-40 \mathrm{~mm}$ & Low & $\begin{array}{l}\text { Low } \\
\text { foundation }\end{array}$ \\
\hline $50-90 \mathrm{~mm}$ & Medium & Normal concrete \\
\hline$>100 \mathrm{~mm}$ & High & \\
\hline (Lyons, 2014) [4] &
\end{tabular}

\subsection{Influental Variable to Slump Value}

In his research, Kardiyono referred to changes in the value of slump according to the amount of water, the ratio of aggregate cement, water-cement ratio and aggregate properties (Tjokrodimuljo, 1998) [5]. Based on Pielert, 2006, the value of slump depends on the number and type of cement, consistency, sand gradient, sand form, gradient and gravel shape, additional material, air percentage, number and characteristics of additional materials, quantity and characteristics of materials and transit time [6]

\subsection{Regression}

Regression analysis was chosen because multiple linear regression is the basic method of prediction in statistics. The stages of testing are carried out in 3 phases, namely:

- Test linearity using scatter diagrams that are useful for viewing data distribution.

- Classic assumption test in the form of: multicollinearity test, non autocorrelation test, non heteroscedasticity test and normality test which is useful to see the suitability of the data.

- Regression test to find the most appropriate modeling of slump values and determine the most influential predictor variables on the value of slump.

The linear regression equation is:

$$
\mathrm{Y}=\beta 0+\beta 1 \mathrm{X} 1+\beta 2 \mathrm{X} 2+\ldots \ldots . .+\beta \mathrm{nXn}
$$


The hypothesis of the regression model uses p-value

$\mathrm{H} 0: \beta \mathrm{j}=0$

$\mathrm{H} 1: \beta \mathrm{j} \neq 0$

- $\alpha<0.05$ then $\mathrm{H} 0$ is rejected if $\mathrm{H} 1 \neq 0$ then the coefficient $\mathrm{X}$ contributes

- $\alpha>0.05$ then H0 is not rejected, even though $\mathrm{H} 1 \neq 0 \mathrm{X}$ coefficient does not have a significant contribution to $\mathrm{Y}$

The selection of regression is best sought by looking for the values the highest $\mathrm{R}^{2}$ and adj. $R^{2}$ and its accuracy are validated in the diagram and the MSE value. The influential variable is obtained from the standard coefficient value with $\mathrm{p}$-value $<0.05$.

\section{RESEARCH METHODOLOGY}

\subsection{Research concept}

Ideally the value of the slump must be stable starting from batching, mixing, transporting to pouring. The consistency of the concrete mixture can change due to the temperature and transit time in the site. The rotation of the mixer truck restrain hardening, but the nature of the plasticity will decrease. Therefore, modeling to predict slump values can be used to minimize the trial and error process when making job mix proportions. Appropriate modeling can be used to predict the value of the concrete mix slump as a form of quality management supervision.

\subsection{Research Flow}

This study produces appropriate modeling and the variables that most influence the slump value. Output is obtained by analyzing primary data in two stages, there is: test assumptions and regression analysis. Test assumptions are useful for verifying data, so that the resulting regression modeling is not biased. The second processing is regression analysis to get the appropriate prediction model and most influential variable. The appropriate model is selected from the highest $\mathrm{R}^{2}$ and adj. $\mathrm{R} 2$ value and also the smallest Mse value and diagram. The output regression analysis not only $\mathrm{R}^{2}$ but also standard coefficients for each predictor variable. The standard coefficient that have $\mathrm{p}$-value $<0.05$ indicates that the variable has a significant effect on the value of slump.

\section{RESULT AND DISCUSSION}

\subsection{Empirical Data}

The data obtained is a mutual quality check. The mutual check sheet for each batching plant varies according to the company format. Data amounted to 56 mixes with variations in type and amount of material. Data has varying compressive strengths, namely: BO, K-125, K-175, K-225, K-250, K-275, K$300, \mathrm{~K}-350, \mathrm{~K}-450, \mathrm{~K}-500$. The amount of each material based on compressive strenght also varies. Data is used entirely without being categorized based on strong characteristics.

To deepen the analysis of the study, the data will be divided according to the ratio of sand-aggregate with a division of $<38 \%, 38$ $44 \%$ and $>44 \%$. Jobmix materials as predictor variables with the following names: cement (X1), water (X2), sand (X3), gravel $5-10 \mathrm{~mm}$ (X4), gravel $10-20 \mathrm{~mm}$ (X5), gravel $20-30 \mathrm{~mm}$ (X6), rock dust (X7), fly ash (X8), retarder (X9) and superplasticizer (X10) and the response variable is the target slump (Y).

\subsection{Analysis}

Data divided into 3 part according sand ratio there is sand ratio $<38 \%$, ratio $38-44 \%$, and $>44 \%$ (Table 2). Each classification have vary compressive strenght and materials.

Table 2. Classification Data

\begin{tabular}{lll}
\hline Classification & Number & Variable predictor \\
\hline Sand ratio $<38 \%$ & 18 & 10 \\
\hline Sand ratio $38-44 \%$ & 29 & 10 \\
\hline Sand ratio $>44 \%$ & 7 & 8 \\
\hline
\end{tabular}

\subsubsection{Analysis of rasio pasir $<38 \%$}

Data on sand ratio analysis $<38 \%$ has 18 mixed data. Predictor variables that can be categorized are 10 variables. The sand ratio data range $<38 \%$ is shown in Table 3 . The collected data is included in medium and high workability.

The result of test classic assumption, there is variables having VIF value >10 (Table 4). It is indicate that there is correlation between independent variables. The variables were cement, sand, gravel 5-10mm, 10-20mm, gravel $20-30 \mathrm{~mm}$ gravel, rock dust, fly ash and retarders. 
Table 3. Data Range of Sand Ratio $<38 \%$

\begin{tabular}{lcc}
\hline \multicolumn{1}{c}{ Variable } & Min & Max \\
\hline Cement & 252 & 541 \\
\hline Water & 146 & 215 \\
\hline Sand & 472 & 761 \\
\hline Gravel 5-10mm & 0 & 318 \\
\hline Gravel 10-20mm & 384 & 1181 \\
\hline Gravel 20-30mm & 0 & 471 \\
\hline Rock dust & 0 & 194 \\
\hline Fly ash & 0 & 135 \\
\hline Retarder & 0 & 1,5 \\
\hline Superplasticizer & 0 & 3,46 \\
\hline Slump value & 5 & 12 \\
\hline
\end{tabular}

Table 4. VIF Value Data Sand Ratio <38\%

\begin{tabular}{lrr}
\multicolumn{3}{c}{ Collinearity Statistics } \\
\hline Variable & Tolerance & \multicolumn{1}{c}{ VIF } \\
\hline Cement & 0,005 & 212,097 \\
\hline Water & 0,150 & 6,647 \\
\hline Sand & 0,007 & 137,006 \\
\hline Gravel 5-10mm & 0,012 & 81,306 \\
\hline Gravel 10-20mm & 0,001 & 704,613 \\
\hline Gravel 20-30mm & 0,003 & 369,349 \\
\hline Rock dust & 0,006 & 170,046 \\
\hline Fly ash & 0,026 & 38,948 \\
\hline Retarder & 0,004 & 271,527 \\
\hline Superplasticizer & 0,151 & 6,606 \\
\hline
\end{tabular}

Analysis regression using this data has a p-value less than 0.05 with values $R^{2} 0.957$ and adj. $\mathrm{R}^{2} 0.897$. So, the model can used to predict slump value accurately as in equation 2 . Multicollinearity only affects the partial test of independent variable.

$Y=-146,837+0,079 x_{1}+0,147 x_{2}+$ $0,114 x_{3}+0,009 x_{4}+0,029 x_{5}+0,035 x_{6}+$ $0,065 x_{7}+0,025 x_{8}-7,253 x_{9}+0,820 x_{10}$

If multicollinearity variables are issued, namely: cement, gravel $10-20 \mathrm{~mm}$, gravel 20 $30 \mathrm{~mm}$. The results of the multicollinearity assumption test can be seen in Table 5. The test results show no assumption of test violations.

$Y=-19,10+0,1457 x_{2}+0,0075 x_{3}-$

$0,01502 x_{4}-0,0312 x_{7}-0,0212 x_{8}+3,56 x_{9}+$ $0,494 x_{10}$
Modeling of sand ratio data $<38 \%$ which has undergone improvement in assumption test consists of 7 predictor variables with values $\mathrm{R}^{2}$ 0.8236 and adj. $R^{2} 0.7001$. This result indicate that modelling data for predicting slump value on sand ratio $<38 \%$ more accurately using equation 1. Based on standardized coefficient the variables influencing the slump value of model 1 are water and sand. The influential variables of model 2 are: water, rock dust and retarder.

Table 5. Data Value of Sand Ratio <38\% Improvement

Collinearity Statistics

\begin{tabular}{lrc}
\hline & Tolerance & \multicolumn{1}{l}{ VIF } \\
\hline Water & 0,622 & 1,608 \\
\hline Sand & 0,325 & 3,075 \\
\hline Gravel 5-10mm & 0,147 & 6,822 \\
\hline Rock dust & 0,107 & 9,377 \\
\hline fly ash & 0,222 & 4,501 \\
\hline Retarder & 0,305 & 3,277 \\
\hline Superplasticizer & 0,633 & 1,579 \\
\hline
\end{tabular}

\subsubsection{Analysis of Sand Ratio 38-44\%}

Data on sand ratio analysis of $38-44 \%$ had 29 mixed data. Predictor variables that can be categorized are 10 variables. The data range at the sand ratio of $38-44 \%$ is shown in table 6 . Data on this ratio are included in moderate to high workability.

The classic assumption test results on 38$44 \%$ sand ratio data also indicate the presence of multicollinearity characterized by a VIF value $>10$. Variable gravel $10-20 \mathrm{~mm}$ and 20 $30 \mathrm{~mm}$ has multicollinearity problems.

Table 6. Data Range of Sand Ratio 38-44\%

\begin{tabular}{lcc}
\hline \multicolumn{1}{c}{ Variable } & Min & Max \\
\hline Cement & 237 & 512 \\
\hline Water & 123 & 210 \\
\hline Sand & 626 & 871 \\
\hline Gravel 5-10mm & 0 & 288 \\
\hline Gravel 10-20mm & 401 & 1081 \\
\hline Gravel 20-30mm & 0 & 500 \\
\hline Rock dust & 0 & 171 \\
\hline Fly ash & 0 & 110 \\
\hline Retarder & 0 & 1,3 \\
\hline Superplasticizer & 0 & 3 \\
\hline Slump value & 5 & 18 \\
\hline
\end{tabular}


Table 7. VIF Value for Sand Ratio 38-44\%

\begin{tabular}{lcc}
\multicolumn{3}{c}{ Collinearity Statistics } \\
\hline Variable & Tolerance & VIF \\
\hline Cement & 0,128 & 7,832 \\
\hline Water & 0,442 & 2,264 \\
\hline Sand & 0,167 & 5,998 \\
\hline Gravel 5-10mm & 0,118 & 8,501 \\
\hline Gravel 10-20mm & 0,010 & 95,889 \\
\hline Gravel 20-30mm & 0,009 & 110,761 \\
\hline Rock dust & 0,162 & 6,190 \\
\hline fly ash & 0,200 & 5,011 \\
\hline
\end{tabular}

The model formed from regression analysis for sand ratio data is $38-44 \%$, seen from equation 4 with $\mathrm{R}^{2} 0,631$ and adj. $\mathrm{R}^{2}$ 0.4394 .

$$
\begin{gathered}
Y=-40,325+0,024 x_{1}+0,058 x_{2}+ \\
0,009 x_{3}+0,030 x_{4}+0,014 x_{5}+0,025 x_{6}+ \\
0,043 x_{7}+0,063 x_{8}+2,575 x_{9}+1,507 x_{10}
\end{gathered}
$$

Test assumptions and regression analysis were carried out again by removing the multicollinearity variable. If one of the variables between gravel size $10-20 \mathrm{~mm}$ or size $20-30 \mathrm{~mm}$ is issued, multicollinearity does not occur. The highest value $\mathrm{R}^{2}$ and adj. $\mathrm{R}^{2}$ is obtained by removing the gravel material size 10-20mm.

Table 8. VIF Value of Sand Ratio 38-44\% Improvement

\begin{tabular}{lcc}
\multicolumn{3}{c}{ Collinearity Statistics } \\
\hline Variable & Tolerance & VIF \\
\hline Cement & 0,202 & 4,940 \\
\hline Water & 0,444 & 2,255 \\
\hline Sand & 0,168 & 5,936 \\
\hline Gravel 5-10mm & 0,389 & 2,572 \\
\hline Gravel 20-30mm & 0,178 & 5,604 \\
\hline Rock dust & 0,186 & 5,369 \\
\hline Fly ash & 0,328 & 3,052 \\
\hline Retarder & 0,190 & 5,259 \\
\hline Superplasticizer & 0,340 & 2,945 \\
\hline
\end{tabular}

The results of the improvement regression analysis for sand ratio data $38-44 \%$ have a value of $R^{2} 0.6196$ and adj. $R^{2} 0.4394$ on equation 5.

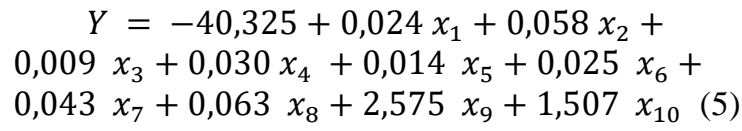

In this category, based on adj. $\mathrm{R}^{2}$ value modelling has the same ability to predict the slump value. The $\mathrm{R}^{2}$ value on equation 3 higher than equation 5 because the variables on equation 4 much more than equation 5 . Based on standardized coefficient value, the most influencing variables on model 3 is fly ash and on model 4 are $20-30 \mathrm{~mm}$ gravel and fly ash.

\subsubsection{Analysis of sand ratio $>44 \%$}

Analysis data on sand ratio $>44 \%$ had 9 mixed data. Predictor variables that can be categorized are 8 variables. Variable rock dust and superplasticizer not included. The data range of the sand ratio $>44 \%$ is shown in Table 9. The data included in moderate to high workability.

Table 9. Data Range of Sand Ratio $>44 \%$

\begin{tabular}{lcc}
\hline \multicolumn{1}{c}{ Variable } & Min & Max \\
\hline Cement & 210 & 394,23 \\
\hline Water & 118 & 193,27 \\
\hline Sand & 780 & 908 \\
\hline Gravel 5-10mm & 129 & 291 \\
\hline Gravel 10-20mm & 409 & 864 \\
\hline Gravel 20-30mm & 0 & 456,87 \\
\hline Fly ash & 0 & 85 \\
\hline Retarder & 0 & 1 \\
\hline Target value & 5 & 10 \\
\hline
\end{tabular}

Analysis the classic assumption of data sand ratio $>44 \%$ is failed. There is correlation between independent variables, autocorrelation and heteroskedastisitas occurs, and the data distribution is not normal. Regression analysis cannot be done because the data cannot be repaired. The method of improvement can be done by increasing the amount of data (n), but no empirical data can be added.

\subsection{Appropriate model}

The results of the analysis show that there are 4 equations that can be formed from 56 study data by dividing them according to the ratio of sand. The used variables can be reduced due to violations of assumptions. Comparison of the values of $\mathrm{R}^{2}$, adj $\mathrm{R}^{2}$ and MSE can be seen from table 10. Equations with the highest values of $\mathrm{R}^{2}$ and adj. $\mathrm{R}^{2}$ and the smallest MSE value is the equation for the data 
ratio $<38 \%$ without improvement (model 1). The selection of sand ratio models $<38 \%$ is strengthened by the diagram in Figure 1. The predicted slump value of the equation 1 has a pattern that approximates the actual slump pattern. So the appropriate model for predicting concrete slump values accurately is model sand ratio $<38 \%$ (model 1). Modeling can be used to predict slump values for data that included in range data according to Table 2.
Table 10. Value of $\mathrm{R}^{2}$, adj. $\mathrm{R}^{2}$ AND MSE

\begin{tabular}{lccc}
\hline \multicolumn{1}{c}{ Equation } & $\mathrm{R}^{2}$ & $\begin{array}{c}\text { Adj. } \\
\mathrm{R}^{2}\end{array}$ & $\mathrm{MSE}$ \\
\hline$<38 \%$ & 0,957 & 0,897 & 0,31 \\
\hline$<38 \%$ improvement & 0,8236 & 0,7001 & 1,29 \\
\hline $38-44 \%$ & 0,631 & 0,426 & 3,10 \\
\hline $38-44 \%$ improvement & 0,426 & 0,4394 & 3,19 \\
\hline
\end{tabular}

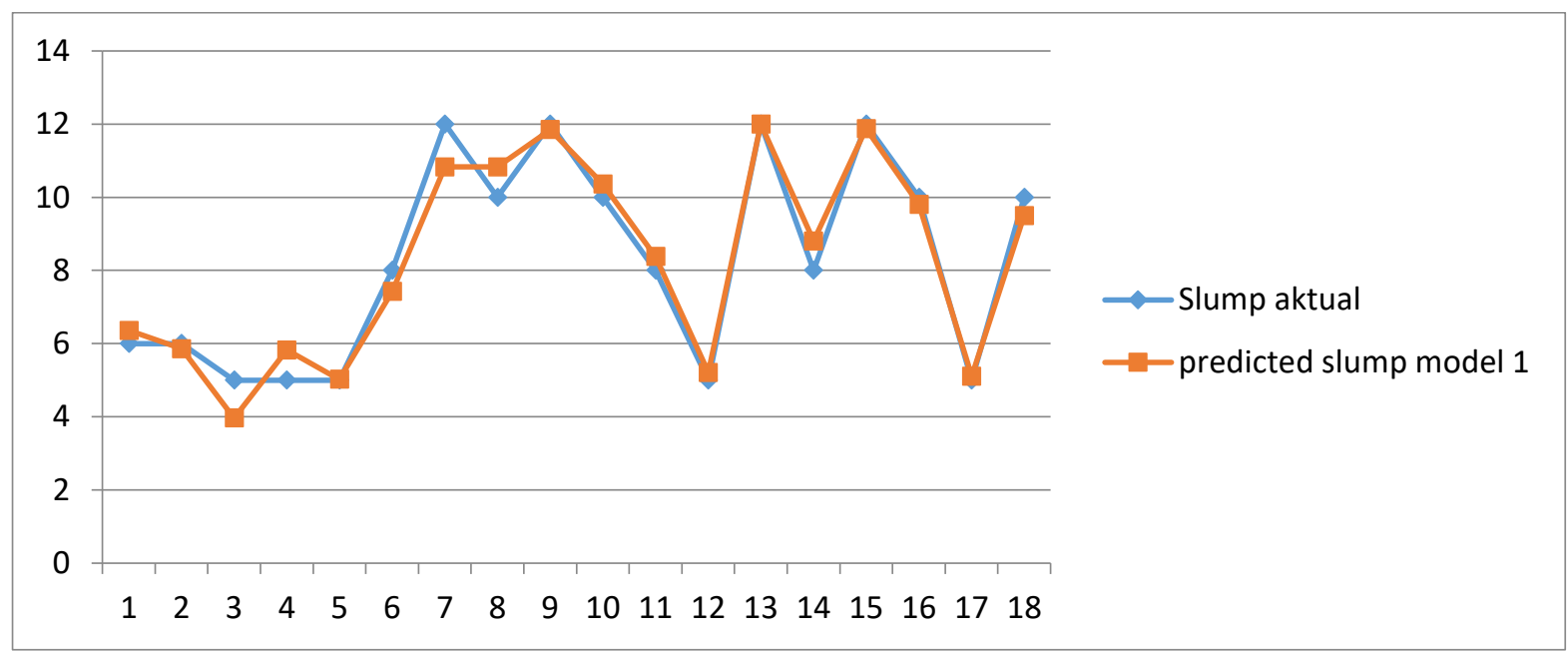

Figure 1. Comparison of Actual Slump Values With Slump Predictions of Model 1 (Data Sand Ratio

\subsection{Influential variable of slump value}

Based on the standard coefficients in the regression analysis, the p-value $<0.05$ of model 1 was seen in the variable water and sand. These variables show the highest influential variable on the predicted slump value based on statistic. In equation the most influencing variables having large coefficient than other materials. Water and sand have positif simbol and great coefficient. Every $1 \mathrm{~kg} / \mathrm{m}^{3}$ of each water dan sand added will increase the slump value by $0,147 \mathrm{~cm}$ and $0,114 \mathrm{~cm}$. In theory, consistency of fresh concrete is related to water content. Measurement water content depends on moisture content of materials, gradation of aggregate and temperature variation.

Measurement moisture content of solid material related to the water arbsorption of material it selves. The highest effect of moisture content on aggregate, because the amount of this variable in job mix approximately $70-80 \%$. The ideal moisture content of aggregate in saturated condition, but it is too difficult to measure. Cement also need
$<38 \%$ ) water for hydration.

Aggregate gradation influencing water measurement based on dimension and quantity. The larger size of aggregate will require more water to lubricate the surface, but in concrete mass the number is less. Thats why, the more little size with a great number of quantity required more water than the larger one.

On fresh concrete there are two temperature that influencing water requirement. Concrete temperature due to hydration and ambient temperature. That temperature related to evaporation of water.

\section{CONCLUDING AND SUGGESTION} 5.1. Conclusion

Based on the results and discussion can be drawn as follows:

1. The most suitable modeling can be obtained using multiple linear regression. Model 1 is the most suitable and accurate in predicting the actual slump value. Degree of accuracy reaches 0,957 for $R^{2}$ and 0,897 for adj. $\mathrm{R}^{2}$. 
2. The most influential variables on slump value in equation 1 is water and sand. Both of it have lerger coefficient than other material and the simbol is positif. Which means, every $1 \mathrm{~kg} / \mathrm{m}^{3}$ of each water dan sand added will increase the slump value by $0,147 \mathrm{~cm}$ and $0,114 \mathrm{~cm}$.

\subsection{Suggestion}

To deepen the analysis of the next study, more than 10 variables can be used. The deeper variables increase affect the slump value such as: evaporation, hydration, transit time, aggregate absorption rate, concrete temperature, ambient temperature and moisture content, will increase sharpness study. Other variables such as aggregate-cement ratio, FAS, aggregate max, aggregate gradient can be used for grouping data as in this study. To sharpen the next study, additional amount of data is much better.

\section{REFERENCES}

[1] Murdock, A. J. (1986). Material and Concrete practice. Jakarta: Erlangga (in bahasa).

[2] JSCE, J. S. (2010). Standard Specification for Concrete Structures 2007 "Materials and Construction". Japan: JSCE concrete committee.

[3] National Standarisation organisation. (2008). SNI 1972-2008 Concrete Slump Test. Jakarta: Badan Standarisasi Nasional (in bahasa).

[4] Lyons, A. (2014). Material for Architects and Builder Fifth Edition. New York: Routledge Taylor and Francis Group.

[5] Tjokrodimuljo, K. (1998). Faktors that affecting the thickness of concrete mixtures and their application to concrete mortar planning. Media Teknik No. 1 Year XX February edition , 44-49 (in bahasa).

[6] Pielert, J. F. (2006). Significance of Test and Properties of Concrete and Concrete-Making Materials. USA: ASTM International. 